\title{
Station-based deconstructed training model for teaching procedural skills to medical students: a quasi-experimental study
}

This article was published in the following Dove Press journal:

Advances in Medical Education and Practice

4 October 2010

Number of times this article has been viewed

\author{
Seyyed M Razavi' \\ Mojgan Karbakhsh' \\ Mahdi Panah Khahi ${ }^{2}$ \\ Soheila Dabiran' \\ Sara Asefi ${ }^{3}$ \\ Ghamar H Zaker Shahrak ${ }^{4}$ \\ Ali R Bad Afrooz ${ }^{4}$ \\ 'Department of Community Medicine, \\ ${ }^{2}$ Department of Anesthesiology, \\ ${ }^{3}$ Department of General Practice, \\ ${ }^{4}$ Clinical Skills Center, Tehran \\ University of Medical Sciences, Iran
}

Background: Every procedural skill consists of some microskills. One of the effective techniques for teaching a main procedural skill is to deconstruct the skill into a series of microskills and train students on each microskill separately. When we learn microskills, we will learn the main skill also. This model can be beneficial for tuition on procedural skills.

Objective: In this study, we propose a stationed-based deconstructed training model for tuition of each microskill, and then we assessed the medical students' self-perceived abilities.

Methods: This quasi-experimental study was conducted in 268 medical students (536 matched pre- and post-questionnaires) at the surgical clerkship stage during five consecutive years in three teaching and learning groups. In this study, we taught each skill in 10 steps (proposed model) to the students. We then evaluated the students' self-perceived abilities using a pre- and post-self-assessment technique. SPSS v13 software with one-way analysis of variance and paired $t$-tests were used for data collection and analysis.

Results: Assessment of medical students' perceived abilities before and after training showed a significant improvement $(P<0.001)$ in both cognitive and practical domains. There were also significant differences between the three teaching and learning groups $(P<0.001)$. There were no significant differences for the different years of training regarding the observed improvement.

Conclusion: This study suggests that deconstructing the practical skills into microskills and tuition of those microskills via the separated structured educational stations is effective according to the students' self-ratings.

Keywords: clinical skills center, microskills, perceived ability, self-assessment, self-scoring stationed training

\section{Introduction}

Training of medical students on clinical procedural skills is an important component of medical curricula. Students can learn procedural skills via new methods, such as simulated models, as effectively as in a true patient care encounter, without risking inadvertent injuries to patients. ${ }^{1}$

Nowadays, clinical skills centers (CSCs) as multidisciplinary units are important structural components of reputable universities throughout the world. In these centers, a variety of methods and techniques have been used for teaching of clinical skills. ${ }^{2,3}$ One of these methods is using stations (the stationed method). ${ }^{4}$

On the other hand, one of the effective techniques for procedural skills training is to deconstruct the considered skills into their microskills. As Rogers et al has indicated: "For skill deconstruction, the instructor should break down the procedure into some small meaningful and more digestible components for teaching purposes. For
Correspondence: Mahdi Panah Khahi Tehran University of Medical Sciences, Sina Hospital, Iman Ave, Tehran, Iran Email panahkha@sina.tums.ac.ir 
example, during teaching the insertion of a central line, one of the microskills that need to be acquired prior to attempting the procedure as a whole is the skill of drawing back on a syringe in a single-handed method. Without accomplishing this smaller component of the motor skill, the physician will never successfully learn to place a central line independently. Therefore, instructors must take the time to deconstruct the components of the procedure in preparation for the learning session". 5

Deconstruction of a complex skill into its simple microskills has been attempted previously by other researchers. For example, as Kuntze et al have quoted in their paper, Ivey divided the complex skills of a counseling interview into small meaningful skills, so-called microskills. In their study conducted in 583 first- and second-year bachelor students at a Dutch University during 2004-2006, Kuntze et al found that the microcounseling method is an effective approach. ${ }^{6}$

The five-step microskills model of clinical teaching, first proposed by Nehler et al in $1992,{ }^{7}$ has been utilized by other authors, including Barrett and $\mathrm{Gopal}^{8}$ to teach learners with different learning preferences. As Barrett reported, the Society of Teachers of Family Medicine now includes the microskills model suggested by Nehler as a standard component in its faculty development series. ${ }^{8}$ Using this approach, if the learners learn each microskill separately (eg, in separated stations), they can also perform the whole skill well.

Barrett and Gopal proposed using the different learning preferences during the teaching process. They discuss that learning is a sensory process that involves a combination of seeing, hearing, and doing. The learners were then categorized as visual, auditory, and tactile learners. Visual learners learn best by seeing (video clips, charts, graphs, pictures, tables, maps, boards), auditory learners prefer listening to educational matters (listening to tapes and oral reports), and tactile learners prefer doing projects. ${ }^{8}$ In fact, educating microskills through separated structured educational stations involves a combination of the senses of learners.

In the present study, we used a combination of deconstructed methods (microprocedures) and stationed training, and then assessed the proposed method by assessing perceived ability of medical students after (in comparison with before) training.

\section{Materials and methods}

This is a quasi-experimental study that introduces a method for tuition of procedural skills to medical students. In this study, we have assessed the perceived ability of medical students to perform certain procedural skills before and after a deconstructed training course. This training course was a part of their surgical clerkship from 2004-2008 at the Tehran University of Medical Sciences in Iran.

The study was conducted in 268 medical students introduced by the surgical departments of three educational hospitals affiliated to the CSC, allocated to groups A, B, and C. The CSC at Tehran University of Medical Sciences was prepared for performing about 500 general clinical microskills in the general medical practice domain. Each of the three groups consisted of about 15-20 medical clerks and five medical faculties, and we designed a mixed theoretic and practical short course for training the students in surgical skills, referred to as station-based deconstructed training (SDT). In this model, we taught each skill in 10 steps as follows:

- Selection of the considered skill

- Presentation of theoretic aspects in the classroom

- Deconstruction of the selected skill into its microskills

- Demonstration of the manner of performing each microskill in the classroom

- Replying to the students' questions

- Setting the conditions for performing each microskill in separated educational stations in the CSC

- Performance of all the microskills by students in all the stations (each station designed for five to six students) in the CSC

- Performing the main skill (containing all the microskills) by one or two students in the classroom in the presence of staff and other students

- Presenting feedback to students

- Practicing by students under supervision of staff at another appropriate time.

In this study, 10 different practical settings were prepared for teaching 10 microsurgical skills in 10 distinct educational stations. Students could learn every microskill under direct supervision of their faculties. Three medical skills selected were suturing, nasogastric tube insertion, and urinary catheterization. The 10 microskills were:

- Gloving

- Opening packs, and identifying and using surgical instruments

- Skin antisepsis and performing local anesthesia

- Suturing

- Surgical knotting

- Removal of surgical sutures

- Dressing wounds

- Identifying and selection of urinary catheters 
- Urethral catheterization for males and females

- Insertion of the nasogastric tube.

The total number of courses performed for volunteer hospitals was 17 (nine courses for hospital A, three courses for hospital B, and five courses for hospital C). Randomization was not possible in this study, and the numbers of students and courses were not equal because the students were introduced by the volunteer educational hospitals to the CSC to pass a part of their surgical course. The perceived ability of students for each microskill was assessed before and after each course using structured questionnaires. In a pilot study, the content validity and reliability of the questionnaire was assessed (Cronbach's alpha $=0.85$ ).

At the beginning of all the arranged courses (17 in total), the educational objectives were explained to all participants, and they were shown how to complete and score the questionnaires. The participants then assessed their perceived ability before and after tuition by self-scoring of their knowledge and perceived psychomotor skills from 0 (lowest) to 10 (highest) at the beginning and end of each course. The students were asked to use a code for filling in the questionnaires at the beginning and use the same code at the end of each course.

Of the total 301 pairs of questionnaires (before and after), 33 pairs were excluded (because of absenteeism). Thus, in this study, the final number of students was 268 (536 pre- and post-questionnaires).

The students were assured that the results of the study would not be considered for their formal evaluations, and the results of the assessments were reported as codes. Every code was matched with the same code before and after the study. This research was approved by the Research Committee, Department of Community Medicine, Tehran University of Medical Education. In addition, the Dean of Educational Affairs in the Faculty of Medicine provided the required coordination for training students of medicine using the SDT model.

\section{Statistical analysis}

One-way analysis and paired $t$-tests were used to assess for statistically significant differences using SPSS software (version B; SPSS Inc., Chicago, IL).

\section{Results}

In this study, the self-perceived abilities of 268 medical trainees were assessed in 10 practical microskills and 17 related theoretic subjects by 536 pre- and post-questionnaires.
Table 1 shows the 17 theoretic prerequisite educational themes for 10 microskills and differences between scores before and after tuition. Table 2 shows the 10 microskills and differences in averages of scores before and after tuition by student's self-scoring. The results of students' self-assessment of their knowledge and practice after tuition in structured stations are shown in Table 3.

The average increases in scores, according to students'self-scorings of their self-percieved practical skills, in the three training groups were $4.91( \pm 2.71)$ for Group A, 3.53 $( \pm 2.20)$ for Group B, and $4.58( \pm 2.71)$ for Group C. The scores in the theoretic domain were improved by about $4.93( \pm 2.21)$ in Group A, $3.25( \pm 1.87)$ in Group B, and 4.43 $( \pm 2.32)$ in Group C. Comparing of the scores before and after tuition in the three training groups showed improvement in the knowledge and skills of trainees $(P<0.001)$. These significant differences were also observed among the three training groups $(P<0.001)$ as shown in Table 4 . There were no significant differences among the students' scores in each year from 2004 to 2008 .

\section{Discussion}

For introducing our recommended model, we should clarify the three following important concepts:

- Skill (an affective or psychomotor action)

- Microskill (actions derived from deconstruction of each skill)

- Tuition in structured educational stations.

In this study the skill means only practical activities, and the selected basic surgical skills were similar to those recommended by John Hopkins University for Medical Clerks, except for venepuncture, ${ }^{9}$ and were focused only on psychomotor acts.

Deconstruction of a complex skill into its microskills is a recommended method for procedural tuition. ${ }^{5}$ For example, one study conducted in 18 first- and second-year medical students with no previous exposure to transurethral resection of prostate in the operating room, showed that for acquisition of transurethral resection skills, task deconstruction is superior to full-task training alone. ${ }^{10}$ Kuntze et al also demonstrated that microskills training in the counseling communication domain is a very effective method. ${ }^{6}$ Our findings in this study are compatible with the aforementioned studies.

Other studies have demonstrated structured educational stations to be an acceptable method. ${ }^{4}$ Objective structured clinical examination performed in some stations is a familial abbreviation, but SDT is not a customary abbreviation, 
Table I Results of students' self-scoring onto 17 prerequisite theoretic themes for selected basic surgical skills before and after tuition*

\begin{tabular}{|c|c|c|c|c|c|}
\hline Theoretic themes & Group & $\mathbf{n}$ & $\begin{array}{l}\text { Differences in scores before } \\
\text { and after tuition }\end{array}$ & $\begin{array}{l}\text { Standard } \\
\text { deviation }\end{array}$ & $P$ value \\
\hline Common instruments used in & $A$ & 164 & 5.35 & 2.64 & 0.001 \\
\hline \multirow[t]{2}{*}{ surgical ambulatory procedures } & B & 37 & 3.83 & 2.58 & \\
\hline & C & 66 & 4.16 & 2.72 & \\
\hline Manner of using instruments in & $A$ & 164 & 5.27 & 2.64 & 0.003 \\
\hline \multirow[t]{2}{*}{ surgical ambulatory procedures } & B & 37 & 3.97 & 2.35 & \\
\hline & C & 66 & 4.19 & 2.89 & \\
\hline \multirow[t]{3}{*}{ Common suturing strings and needles } & $A$ & 164 & 5.31 & 3.10 & 0.001 \\
\hline & B & 37 & 3.37 & 3.17 & \\
\hline & C & 66 & 4.40 & 2.90 & \\
\hline \multirow[t]{3}{*}{ Manner of using suturing strings and needles } & A & 164 & $5 / 07$ & $3 / 21$ & 0.011 \\
\hline & B & 37 & 5.35 & 2.80 & \\
\hline & C & 66 & 4.68 & 3.02 & \\
\hline \multirow[t]{3}{*}{ Common disinfectant used in surgery } & A & 164 & 4.86 & 2.91 & 0.001 \\
\hline & B & 37 & 2.62 & 3.18 & \\
\hline & C & 66 & 2.47 & 3.16 & \\
\hline \multirow[t]{3}{*}{ Traumatic wound examination principles } & A & 164 & 4.53 & 3.15 & 0.004 \\
\hline & B & 37 & 3.13 & 3.03 & \\
\hline & C & 66 & 4.16 & 2.91 & \\
\hline \multirow[t]{3}{*}{ Preparing wounds for reconstruction } & A & 163 & 4.65 & 3.80 & 0.007 \\
\hline & B & 37 & 3.45 & 3.27 & \\
\hline & C & 66 & 3.68 & 3.32 & \\
\hline \multirow[t]{3}{*}{ Drugs used in local anesthesia } & A & 164 & 4.87 & 3.08 & 0.008 \\
\hline & B & 37 & 3.29 & 2.28 & \\
\hline & C & 66 & 4.03 & 3.15 & \\
\hline \multirow[t]{3}{*}{ Method of local anesthesia } & $A$ & 164 & 2.52 & 3.10 & 0.001 \\
\hline & B & 37 & 3.45 & 2.93 & \\
\hline & C & 66 & 4.42 & 3.16 & \\
\hline \multirow[t]{3}{*}{ Types of sutures and knots } & A & 164 & 5.90 & 2.67 & 0.001 \\
\hline & B & 37 & 3.29 & 3.33 & \\
\hline & C & 66 & 5.39 & 2.84 & \\
\hline \multirow[t]{3}{*}{ Indications of suturing } & $A$ & 164 & 5.43 & 2.67 & 0.001 \\
\hline & B & 37 & 3.89 & 3.33 & \\
\hline & C & 66 & 5.22 & 2.84 & \\
\hline \multirow[t]{3}{*}{ Wound bandaging principles } & $A$ & 164 & 4.51 & 3.01 & 0.001 \\
\hline & B & 37 & 3.48 & 2.57 & \\
\hline & C & 66 & $4 / 63$ & $3 / 07$ & \\
\hline \multirow[t]{3}{*}{ Suturing cares } & $A$ & 164 & 5.31 & 3.58 & 0.019 \\
\hline & B & 37 & 3.21 & 3.12 & \\
\hline & C & 66 & 4.96 & 2.83 & \\
\hline \multirow[t]{3}{*}{ Insertion of nasogastric tubes } & $A$ & 164 & 5.81 & 3.09 & 0.001 \\
\hline & B & 37 & 3.64 & 2.80 & \\
\hline & C & 66 & 5.68 & 3.01 & \\
\hline \multirow[t]{3}{*}{ Urinary catheters } & $A$ & 164 & 4.68 & 3.90 & 0.001 \\
\hline & B & 37 & 3.16 & 3.24 & \\
\hline & C & 66 & 5.64 & 3.45 & \\
\hline Indications and contraindications to urinary & $A$ & 164 & 4.72 & 3.20 & 0.001 \\
\hline \multirow[t]{2}{*}{ catheterization } & B & 37 & 1.86 & 3.31 & \\
\hline & C & 66 & 4.00 & 2.91 & \\
\hline \multirow[t]{3}{*}{ Urinary catheterization manners } & A & 164 & 4.65 & 3.44 & 0.013 \\
\hline & B & 37 & 3.32 & 2.95 & \\
\hline & C & 66 & 5.43 & 2.87 & \\
\hline
\end{tabular}

Note: $*$ Total number of students $=268$ (Group A 165, Group B 37, Group C 66). 
Table 2 Differences of score averages for students' perceived abilities by self-scoring before and after tuition on 10 microskills in stations according to their educational groups

\begin{tabular}{|c|c|c|c|c|c|}
\hline Practical skill & Group & $\mathbf{n}$ & $\begin{array}{l}\text { Differences of score averages, } \\
\text { before and after tuition }\end{array}$ & Standard deviation & $P$ value \\
\hline \multirow[t]{3}{*}{ Gloving } & $A$ & 164 & 1.86 & 3.59 & 0.030 \\
\hline & B & 37 & 1.36 & 2.11 & \\
\hline & C & 66 & 2.04 & 3.74 & \\
\hline \multirow[t]{3}{*}{ Using instruments } & A & 164 & 5.34 & 3.33 & 0.003 \\
\hline & B & 37 & 3.82 & 2.41 & \\
\hline & C & 66 & 3.93 & 3.31 & \\
\hline \multirow[t]{3}{*}{ Local anesthesia } & A & 164 & 5.70 & 3.42 & 0.001 \\
\hline & B & 37 & 2.94 & 3.25 & \\
\hline & C & 66 & 4.46 & 3.58 & \\
\hline \multirow[t]{3}{*}{ Suturing } & A & 164 & 5.89 & 2.99 & 0.001 \\
\hline & B & 37 & 4.02 & 3.26 & \\
\hline & C & 66 & 4.30 & 3.41 & \\
\hline \multirow[t]{3}{*}{ Removal of sutures } & A & 164 & 4.23 & 4.22 & 0.001 \\
\hline & B & 37 & 2.70 & 4.80 & \\
\hline & $\mathrm{C}$ & 66 & 2.42 & 4.21 & \\
\hline \multirow[t]{3}{*}{ Surgical knotting } & $A$ & 164 & 5.90 & 3.61 & 0.002 \\
\hline & B & 37 & 4.44 & 3.91 & \\
\hline & C & 66 & 4.09 & 3.62 & \\
\hline \multirow[t]{3}{*}{ Dressing of wounds } & $A$ & 163 & 3.96 & 4.04 & 0.034 \\
\hline & B & 37 & 2.22 & 3.14 & \\
\hline & C & 66 & 4.01 & 3.16 & \\
\hline \multirow[t]{3}{*}{ Male urinary catheterization } & $A$ & 164 & 4.59 & 3.81 & 0.008 \\
\hline & B & 37 & 3.50 & 3.1 & \\
\hline & C & 66 & 5.34 & 3.26 & \\
\hline \multirow[t]{3}{*}{ Nasogastric insertion } & $A$ & 164 & 6.35 & 3.38 & 0.001 \\
\hline & B & 37 & 4.58 & 3.50 & \\
\hline & C & 66 & 7.13 & 2.54 & \\
\hline \multirow[t]{3}{*}{ Female urinary catheterization } & $A$ & 164 & 5.64 & 4.34 & 0.001 \\
\hline & $\mathrm{B}$ & 37 & 6.88 & 3.54 & \\
\hline & C & 66 & 6.32 & 3.30 & \\
\hline
\end{tabular}

and there are not many studies about this concept in the literature.

In a study conducted in 678 medical students in 2006, Razavi et al showed that training in basic surgical skills in consecutive structured stations without using the patients is an attractive educational method. ${ }^{4}$

In our study, we proposed a combination of deconstruction of skills with stationed education as a

Table 3 The results of students' self-assessments of their knowledge and practices before and after tuition in structured stations in the three groups

\begin{tabular}{|c|c|c|c|c|c|c|c|c|}
\hline \multirow[t]{2}{*}{$\begin{array}{l}\text { Training } \\
\text { group }\end{array}$} & \multirow[t]{2}{*}{$\begin{array}{l}\text { Type of } \\
\text { training }\end{array}$} & \multicolumn{2}{|c|}{$\begin{array}{l}\text { Time of } \\
\text { self-scoring }\end{array}$} & \multirow[t]{2}{*}{$\begin{array}{l}\text { Students } \\
\text { (n) }\end{array}$} & \multirow[t]{2}{*}{$\begin{array}{l}\text { Samples } \\
\text { (n) }\end{array}$} & \multirow[t]{2}{*}{$\begin{array}{l}\text { Mean of score } \\
\text { averages }\end{array}$} & \multirow[t]{2}{*}{$\begin{array}{l}\text { Standard } \\
\text { deviation }\end{array}$} & \multirow[t]{2}{*}{$P$ value } \\
\hline & & Before & After & & & & & \\
\hline \multirow[t]{4}{*}{$A$} & Theoretic & $*$ & $*$ & 165 & 330 & 3.13 & 1.63 & 0.001 \\
\hline & & & & 165 & 330 & 8.12 & 1.25 & \\
\hline & Practical & $*$ & $*$ & 163 & 326 & 3.23 & 2.18 & \\
\hline & & & & 163 & 326 & 8.38 & 1.35 & \\
\hline \multirow[t]{4}{*}{ B } & Theoretic & $*$ & $*$ & 37 & 74 & 4.98 & 2.34 & 0.001 \\
\hline & & & & 37 & 74 & 8.24 & 1.40 & \\
\hline & Practical & $*$ & $*$ & 37 & 74 & 5.11 & 2.76 & \\
\hline & & & & 37 & 74 & 8.64 & 1.65 & \\
\hline \multirow[t]{4}{*}{ C } & Theoretic & $*$ & $*$ & 66 & 132 & 3.65 & 2.43 & 0.001 \\
\hline & & & & 66 & 132 & 8.08 & 1.32 & \\
\hline & Practical & $*$ & $*$ & 66 & 132 & 3.75 & 2.52 & \\
\hline & & & & 66 & 132 & 8.34 & 1.54 & \\
\hline
\end{tabular}


Table 4 Average scores for self-scoring of students on their knowledge and practices in basic surgical skills according to three paired training groups

\begin{tabular}{|c|c|c|c|c|}
\hline $\begin{array}{l}\text { Training } \\
\text { group }\end{array}$ & $\begin{array}{l}\text { Differences of score averages } \\
\text { in practical domain }\end{array}$ & $P$ value & $\begin{array}{l}\text { Differences of score averages } \\
\text { in theoretic domain }\end{array}$ & $P$ value \\
\hline A B & 1.39 & 0.014 & 1.67 & 0.001 \\
\hline$A C$ & 0.34 & 0.001 & 0.50 & 0.354 \\
\hline B C & 1.05 & 0.016 & 1.17 & 0.029 \\
\hline
\end{tabular}

model for tuition of procedural skills. For testing this model, we used a self-assessment questionnaire for evaluation of students' self-perceived ability. Although some researchers have shown that medical trainees are poor self-assessors, ${ }^{11}$ others have confirmed this method. For example, in a study conducted in 142 medical students, a significant association existed between self- and departmental assessments for each of seven parameters in three categories of evaluation (clinical activities, written examination, and oral examinations). In this study, students graded themselves lower than the actual faculty ratings and higher than the actual resident ratings. ${ }^{12}$

The beneficial effects of tuition via structured stations and the self-assessment method are also confirmed by other studies. In a study published in 2005, as part of a six-station objective structured assessment of technical skills, 74 residents at five institutions estimated their overall open and laparoscopic skill level before testing. After completing each station, residents evaluated their overall and global skills performance. This study showed that residents even tended to rate themselves lower than did the faculties. ${ }^{13}$

Other studies have also used perceived ability as a surrogate for educational improvement. For example, in one study conducted in 186 students, a questionnaire addressing self-assessment of self-directed learning ability as well as perceived influence of individual curriculum elements on individual study and self-directed learning was used. ${ }^{12}$ In our study, students' perceived ability was used as the dependent variable.

Our study had some limitations, including:

- Limited information about tuition on psychomotor skills through deconstruction of each skill into microskills

- Limited published information on tuition of practical skills in stations

- Use of self-assessment which is not a powerful method for practical measurement

- Inevitable lack of randomization

\section{Conclusion}

This study suggests that deconstructing practical skills into their microskills and teaching them using separated structured educational stations is effective, according to students' self-ratings. We offer similar training courses for tuition on procedural skills to medical students in other clinical domains, including internal medicine, pediatrics, obstetrics and gynecology, urology, and orthopedics. We also suggest testing the proposed model with more valid assessment tools other than self-assessment or self-perceived ability analysis.

\section{Acknowledgments}

We thank all surgical faculties who cooperated to accomplish the objectives of this project, including all the medical clerks and staff of the CSC who helped collecting data. We would also like to thank Drs Labbaf and Atoof and Mrs Jalali from the CSC affiliated to Tehran University of Medical Sciences.

\section{Disclosure}

The authors report no conflicts of interest in this work.

\section{References}

1. Hao J, Estrada J, Tropez-Sims S. The clinical skills laboratory: A costeffective venue for teaching clinical skills to third-year medical students. Acad Med. 2002;77(2):152.

2. Sutherland LM, Middleton PF, Anthony A, et al. Surgical simulation, a systematic review. Ann Surg. 2006;243(3):291-300.

3. Dacre J, Nicol M, Holroyd D, Ingram D. The development of a clinical skills centre. J R Coll Physicians Lond. 1996;30(4):318-324.

4. Razavi M, Meshkani Z, Panahkhahi M. Teaching and testing surgical skills without using patients. J Med Educ. 2004;6(1):123-128.

5. Rogers RL, Mattu A, Winters M, Martinez J, editors. Practical Teaching in Emergency Medicine. NewYork, NY: Wiley-Blackwell; 2009.

6. Kuntze J, van der Molen HT, Born MP. Increase in counseling communication skills after basic and advanced micro skills training. $\mathrm{Br}$ J Educ Psychol. 2009;79(Pt 1):175-188.

7. Neher JO, Gordon KG, Meyer B, Stevens N. A five-step "micro skills" model of clinical teaching. J Am Board Fam Pract. 1992;5(4): 419-424.

8. Barrett NF, Gopal B. Using the five microskills with different learning preferences. Fam Med. 2008;40(8):543-545.

9. Department of Surgery, Johns Hopkins University. Core objectives of the basic surgical clerkship. Available at: http://www.hopkinsmedicine. org/surgery/education/MedStu/CoreObj. Accessed 2010 Aug 18. 
10. Kishore TA, Beddingfield R, Holden T, Shen Y, Reihsen T, Sweet RM. Task deconstruction facilitates acquisition of transurethral resection of prostate skills on a virtual reality trainer. $J$ Endourol. 2009;23(4): $665-668$.

11. Macdonald J, Williams RG, Rogers DA. Self-assessment in simulationbased surgical skills training. Am J Surg. 2003;185(4): 319-322.
12. Herbert WN, McGaghie WC, Droegemueller W, Riddle MH, Maxwell KL. Student evaluation in obstetrics and gynecology: Self- versus department assessment. Obstet Gynecol. 1990;76(3 Pt 1): 458-461.

13. Lee YM, Mann KV, Frank BW. What drives students' self-directed learning in a hybrid PBL curriculum. Adv Health Sci Educ Theory Pract. 2009 Dec 4. [Epub ahead of print].

\section{Publish your work in this journal}

Advances in Medical Education and Practice is an international, peerreviewed, open access journal that aims to present and publish research on Medical Education covering medical, dental, nursing and allied healthcare professional education. The journal covers undergraduate education, postgraduate training and continuing medical education including emerging trends and innovative models linking education, research, and healthcare services. The manuscript management system is completely online and includes a very quick and fair peer-review system. Visit http://www.dovepress.com/testimonials.php to read real quotes from published authors.

Submit your manuscript here: http://www.dovepress.com/advances-in-medical-education-and-practice-journal 